\title{
Effects of Rosin Sizing Agent on the Fixation of Boron in Styrax tonkinensis Wood
}

\author{
Thi Thanh Hien Nguyen ${ }^{1, *}$, Shujun $\mathrm{Li}^{2}$ \\ ${ }^{1}$ Wood Industry College, Vietnam National University of Forestry, Ha Noi, Viet Nam \\ ${ }^{2}$ Material Science and Engineering College, Northeast Forestry University, Haerbin, China
}

Email address:

hienvkt@yahoo.com (T. T. H. Nguyen), lishujun_1999@yahoo.com (Shujun Li)

*Corresponding author

\section{To cite this article:}

Thi Thanh Hien Nguyen, Shujun Li. Effects of Rosin Sizing Agent on the Fixation of Boron in Styrax tonkinensis Wood. Advances in Biochemistry. Vol. 5, No. 4, 2017, pp. 67-72. doi: 10.11648/j.ab.20170504.13

Received: May 5, 2017; Accepted: June 5, 2017; Published: July 13, 2017

\begin{abstract}
The aim of this study was to evaluate the effect of rosin upon fixing boron in Styrax tonkinensis (Piere) wood treated with mixtures of $3 \%$ boric acid and $1 \%$ rosin sizing agent. After treatment, wood samples were also analyzed by scanning electron microscope observation and energy-dispersive X-ray spectroscopy (SEM-EDX). The results showed that all boron-rosin formulations impregnated Styrax tonkinensis wood evenly penetrated into the wood blocks. Boron-rosin treatment decreased by $16 \%$ the amount of boron leaching from treated wood samples compared with those from the samples treated with boric acid alone. The SEM-EDX analysis proved that the boron element was still in the cell lumens of leached wood blocks. Results indicated that rosin emulsion sizing agent can have an effect on the fixation of boron in wood. This signifies that using of rosin as fixing agents may contribute to lead to wood treated with boron based preservatives being more widely used.
\end{abstract}

Keywords: Boron, Fixation, Leaching Resistance, Rosin, Boron-Rosin

\section{Introduction}

Boron compounds exhibit good biocidal activities when used in wood preservative formulations. Nevertheless, they have limited utility in outdoor applications due to their high solubility in water which cause leaching from impregnated wood (Yalinkilic, 2000). Therefore, several fixation systems to limit or decrease boron leachability from treated wood have been developed. For example a combination of boron with: glycerol/glyoxal, vinyl monomers, silanes, alkydes, tall oil derivates, protein, water repellent compound, liquefied wood, and montan wax emulsions (Köse et al., 2011; Obanda et al., 2008; Lesar et al., 2009, 2012; Sen et al., 2009; Temiz et al., 2008; Tomak et al., 2011). However, due to the high costs or a two-step treatment, the above-mentioned approach could have not been deployed in practice.

Rosin is a product obtained from pines and some other plants. It is abundant, natural, and renewable. The major component of rosin is abietic acid, a partially unsaturated compound with three fused six-membered rings and one carboxyl group (Song, 2002).
Therefore, it has a good hydrophobic property. Over the years, rosin was extensively applied in the paper industry as a sizing agent (Zhang, 2005). In our earlier investigations, the rosin sizing agent was used to impregnate poplar wood and the results showed that the rosin sizing agent can reduce the moisture absorption ability of poplar wood and contributes to improving wood decay resistance (Nguyen et al., 2012; Li et al., 2009, 2011). This paper presents results from a preliminary study to reduce the leachability of boron using a naturally derived product - the rosin sizing agent to develop new formulations for wood preservation.

\section{Materials and Methods}

\subsection{Material Preparations}

Styrax tonkinensis (Piere) wood was selected according to the Chinese standard GB 1929 (2009) (same as ISO 3129). Wood specimens were cut from untreated Styrax tonkinensis sapwood into wood blocks with dimensions of $20 \times 20 \times 20$ $\mathrm{mm}$. Deficiency-free cubes were selected for the tests. The 
weight differences of the chosen blocks did not exceed $0.5 \mathrm{~g}$.

The anionic rosin emulsion sizing agent $(\mathrm{R})$ was an industrial product and was supplied by Guangxi Wuzhou Arakawa Chemical Industries Co., Ltd. In this study, it was used to impregnate into wood at the concentration of $1 \%$. And $3 \%$ Boric acid $\left(\mathrm{H}_{3} \mathrm{BO}_{3}\right)$ was provided by Tianjin Kermel Chemical Reagent Co., Ltd., was used as a preservative salts. It was also combined with the rosin emulsion sizing agent to impregnate wood.

\subsection{Treating Wood Blocks}

Before treatment, all sapwood blocks were oven-dried at $103^{\circ} \mathrm{C}$ overnight, weighed to the nearest $0.01 \mathrm{~g}$ and recorded as $\mathrm{W}_{1}$. The blocks were then vacuum-treated with the treatment solution. The vacuum was applied for $30 \mathrm{~min}$ at 0.1 $\mathrm{MPa}$ before supplying the solution into the chamber. After the application another $30 \mathrm{~min}$ at $0.1 \mathrm{MPa}$ vacuum diffusion period followed. Then, the blocks were kept in the treatment solution at ambient conditions until complete saturation. The blocks were then individually removed from the solution, wiped lightly to remove solution from the wood surface, and immediately weighed to the nearest $0.01 \mathrm{~g}$ to determine the mass after impregnation $\left(\mathrm{W}_{2}\right)$. The theory retention of each block was calculated using the following formula:

$$
\text { Theory retention, } \mathrm{kg} / \mathrm{m}^{3}=\frac{G C}{V} \times 10
$$

where $\mathrm{G}=\mathrm{W}_{2}-\mathrm{W}_{1}$ is the weight in grams of the treating solution absorbed by the block, $\mathrm{C}$ is the weight (g) of preservative in 100 grams of treating solution, and $\mathrm{V}$ is the volume of the block in cubic centimeters.

After calculating the retention, the treated samples were air-dried for 48 hours, and oven-dried at $103^{\circ} \mathrm{C}$ overnight, and then weighed to determine the dry weights of the wood blocks after treatment. The difference between the dry weights before and after treatment is the actual retention of each block. And the percentage of actual retention to the theory retention was regarded as the treatability of each preservative formulation.

\subsection{Leaching Treated Wood Blocks}

Leaching of boron was determined according to the standard of the American Wood Preservers' Association E11(AWPA E11 2007). Twelve blocks per treatment were air-dried, then immersed in beakers of distilled water over which a vacuum was applied for $30 \mathrm{~min}$. Then the vacuum was released and the wood blocks were immersed in the distilled water. After $6 \mathrm{~h}$, $24 \mathrm{~h}, 48 \mathrm{~h}$, and 48-h intervals the leaching water was removed and replaced with an equal amount of fresh distilled water.
Leaching was carried out for a total of 14 days. All leachates were collected and kept for boron analysis.

\subsection{Boron Analysis}

In order to measure the contents of boron leached from the treated wood blocks, the leachates were analyzed by using the azomethine-H method described by John et al. (1975) and following American Wood Preservers' Association standard method (AWPA A2-07).

\subsection{Microscopic Observation}

Small samples of dimensions $10 \times 10 \times 1 \mathrm{~mm}$ were cut from the untreated control and the treated wood blocks, and located $3 \mathrm{~mm}$ from each radial, tangential, and transverse surface of the wood block. Each sample was mounted on a metal stub with adhesive, and then they were placed under vacuum and were sputter-coated with a thin layer (approximately $20 \mathrm{~nm}$ thick) of gold. The samples were then observed with a scanning electron microscope (SEM, FEI Quanta 200, USA) at an accelerating voltage of $20 \mathrm{kV}$. Random observations were made on different structures to identify the existence of boron in the anatomical structure of the samples. The element composition was determined by regional analysis using an energy dispersive X-ray spectrometer (EDX) combined with the SEM.

\section{Results and Discussion}

\subsection{Retention Results}

Retention levels of Styrax tonkinensis wood samples treated with boron-rosin solutions (as kilograms per cubic meter) and the actual percent retention of preservative formulations in wood blocks are recorded in Table 1. Total uptake of the treating solution in Styrax tonkinensis wood, including both rosin alone and in combination with boron, were relatively uniform. The actual retention of the rosin sizing agent alone or boron-rosin preservative was very close to theory retention. The actual percent retention of preservative solution containing rosin only or containing boric acid was $92.97 \%$ and $97.74 \%$, respectively. However, when rosin sizing agent combined with boric acid to impregnate wood, the actual percent retention of presevative solution was $96.41 \%$. Results indicate that the concentration of the solutions considered to impregnate Styrax tonkinensis wood using the impregnation method described did not influence the penetration of the preservative complexes into the wood blocks. Which could be proved by SEM analysis.

Table 1. Retention levels and treatability of wood samples treated with boron-rosin solutions.

\begin{tabular}{llll}
\hline Abbreviation & Concentrations & Theory Retention $\left(\mathbf{k g} / \mathbf{m}^{\mathbf{3}}\right)$ & Actual Retention $\left(\mathbf{k g} / \mathbf{m}^{\mathbf{3}}\right)$ \\
\hline 1 & $1 \% \mathrm{R}+3 \% \mathrm{H}_{3} \mathrm{BO}_{3}$ & $26.15(1.07)^{\mathrm{b}}$ & Treatability $\mathbf{( \% )}^{\mathrm{a}}$ \\
2 & $3 \% \mathrm{H}_{3} \mathrm{BO}_{3}$ & $17.12(0.97)$ & $96.41(10.31)$ \\
3 & $1 \% \mathrm{R}$ & $6.47(0.47)$ & $16.74(1.66)$ \\
\hline
\end{tabular}

Note: ${ }^{\text {a }}$ Treatability refers to the percentage of actual retention to the theory retention.

${ }^{\mathrm{b}}$ All results are means of 24 samples. Standard deviations are in brackets. 


\subsection{Boron Leaching}

The amount of boron ions released from the wood samples treated with boric acid solution alone or in combination with rosin at different time intervals are presented in Fig. 1. The results show that a large amount of boron ions was leached out from the wood samples treated with boric acid alone. After 14 days of leaching, $1338 \mathrm{mg}$ of boron was leached out from the samples. However, after $1 \%$ rosin sizing agent was added, the observed leaching of the boron was $1122 \mathrm{mg}$, in comparison to the treated samples with boric acid alone, the extent of boron leaching reduced was $16 \%$. These results suggest that the rosin can contribute to improving boron fixation in wood. This was probably due to the hydrophobic property of rosin. After having penetrated into the wood blocks, the rosin molecules present in the cell lumen and forming an adhesive film that covers the boron crystals (Nguyen et al., 2013). During the leaching process, the rosin acted as a barrier that slowed down boron release from deep inside of the samples, which resulted in the reduction of the boron ion diffusing from wood during the leaching process.

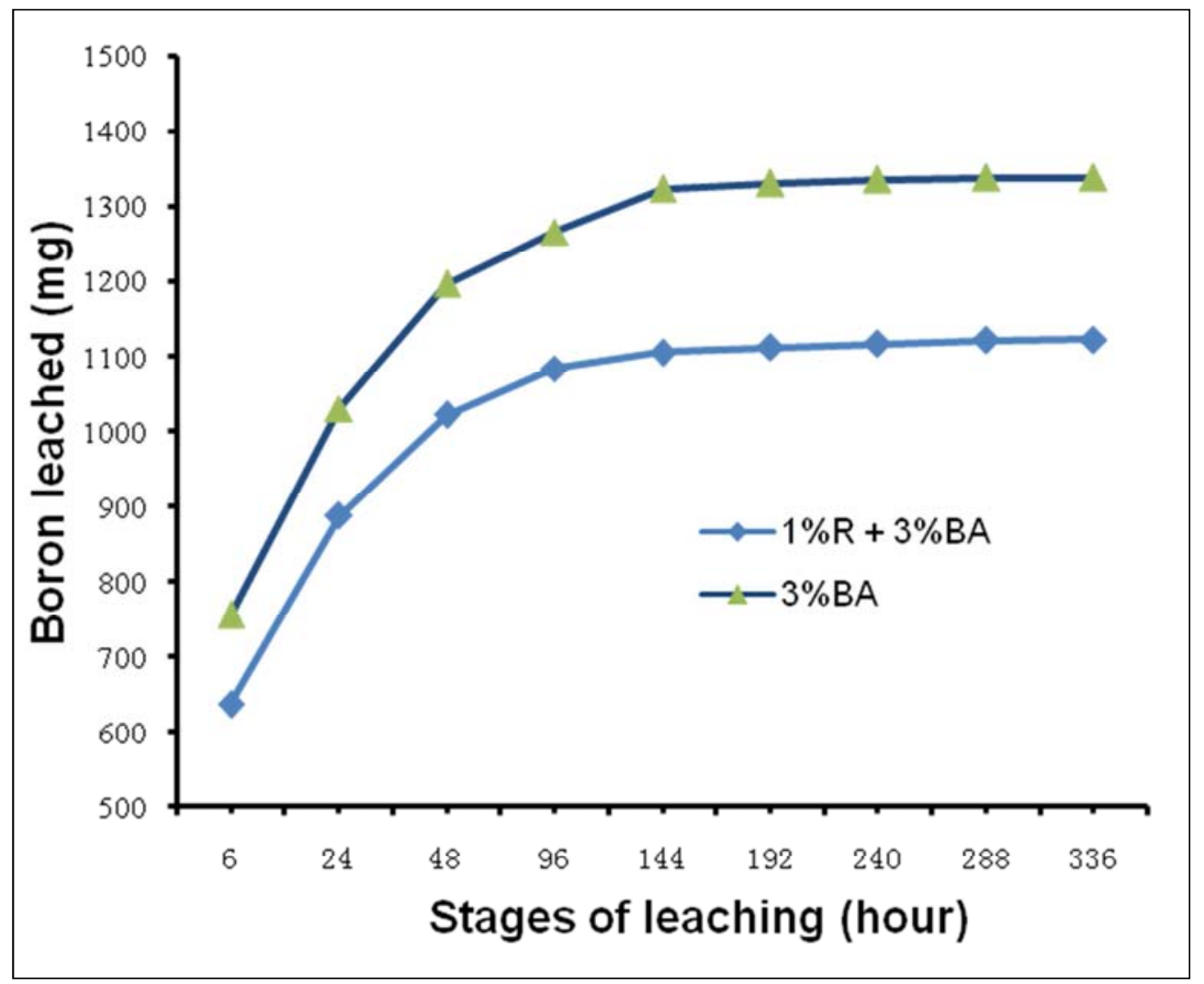

(BA: boric acid $\left(\mathrm{H}_{3} \mathrm{BO}_{3}\right), \mathrm{R}$ : rosin sizing agent)

Figure 1. Boron released from the treated wood samples at different time intervals.

\subsection{Microscopic Observation}

Fig. 2 shows the SEM images of the wood sample before and after treatment. untreated control and wood samples treated with boron-rosin solutions. It can be clearly seen that surface of wood cell wall of the control sample was extremely smooth and no preservative complexes was detected in any part of the untreaed control wood blocks (Fig. 2a). When the wood blocks treated with only boric acid were observed, various crystal particles were found in the cell lumens (Fig. 2b). The spot analysis using SEM-EDX proved that these particles contained B (Fig. 3ab). When the wood blocks treated with rosin alone, various spherical agglomerates were easily detected in the cell lumen (Fig. 2c). However, unlike the crystals in Fig. 2b or spherical agglomerates in Fig. 2c, various spherical agglomerates were easily detected in the cell lumen of the wood blocks treated with boron-rosin formulation, these agglomerates were tightly adhered to the wood cell wall (Fig. 2d). The spectrum obtained from the spot analysis confirmed that these agglomerates contained the element B and they had a lower $\mathrm{B}$ content in comparison to that observed in the crystal particles (Fig. 3cd). This signifies that under the action of vacuum pressure boron-rosin solution could easily penetrated into the wood blocks. 


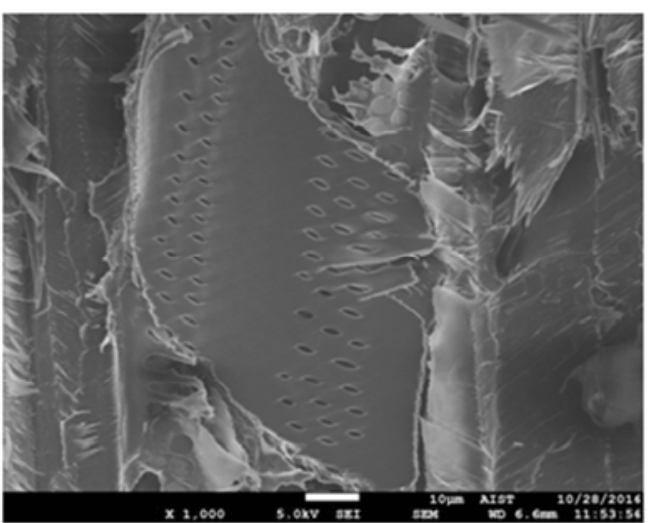

a)

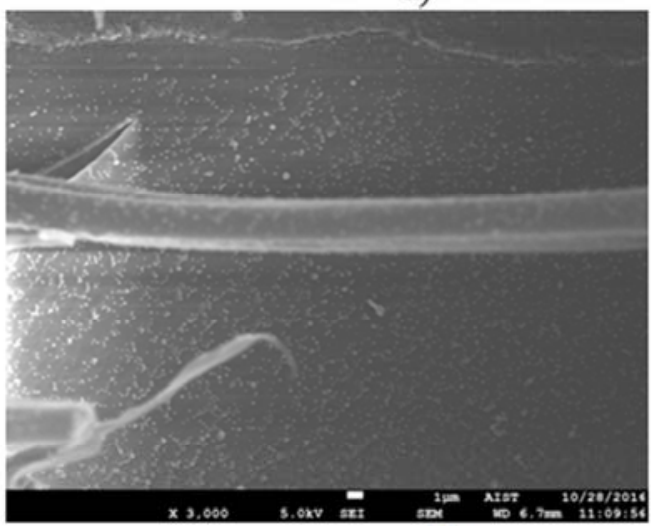

c)

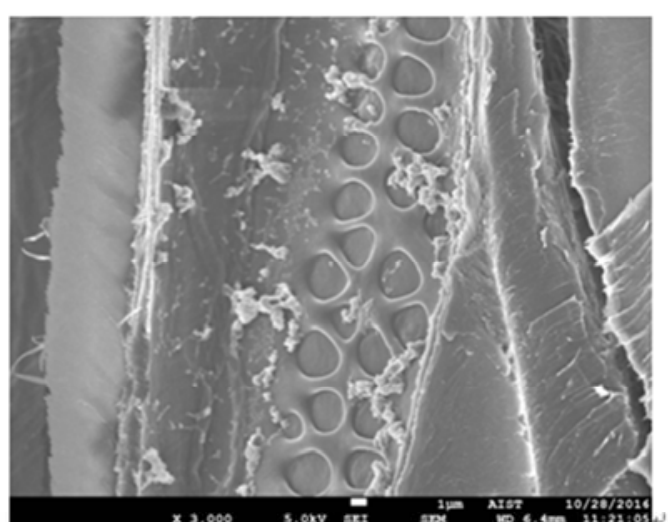

b)

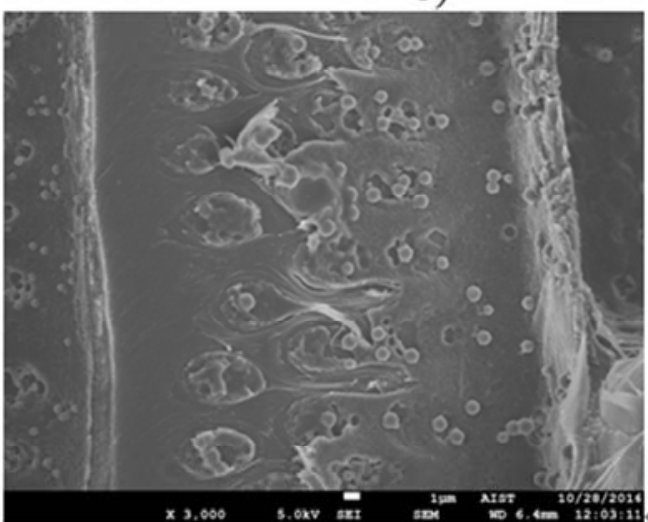

d)

Figure 2. SEM images of tangential section of control wood block (a) and boric acid alone (b), rosin alone (c) and boron-rosin treated wood samples (d).

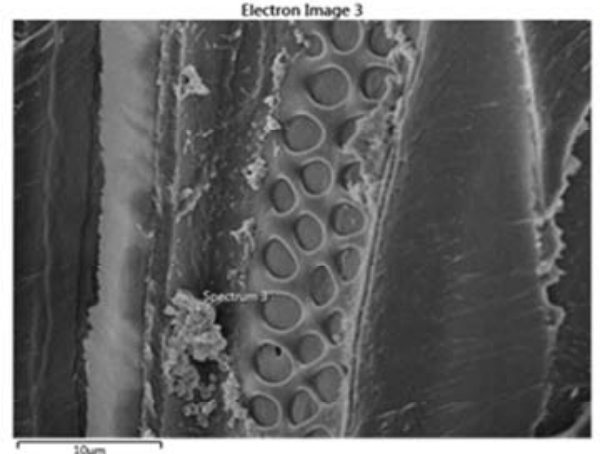

a)

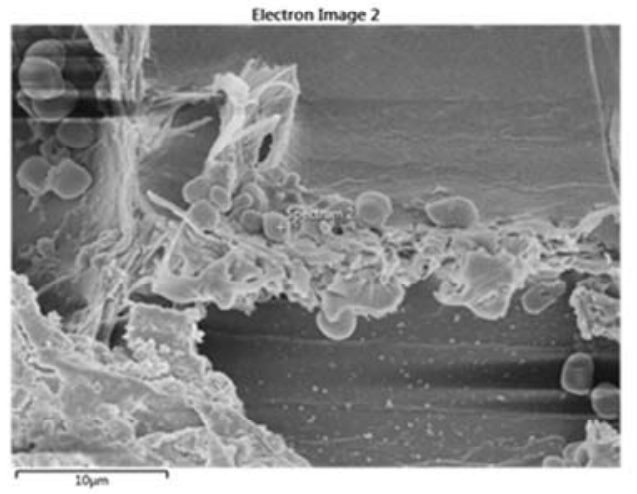

c)

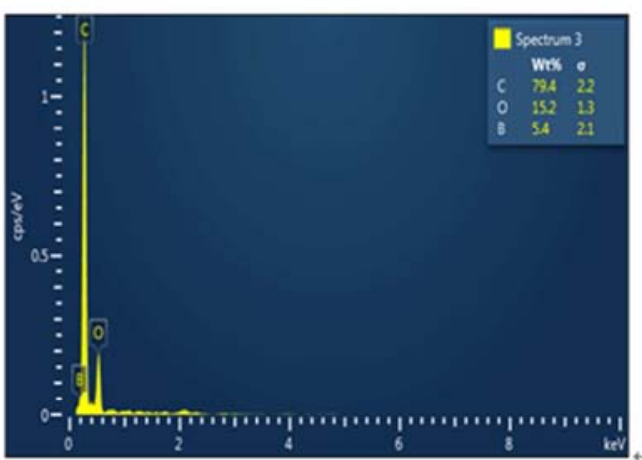

b)

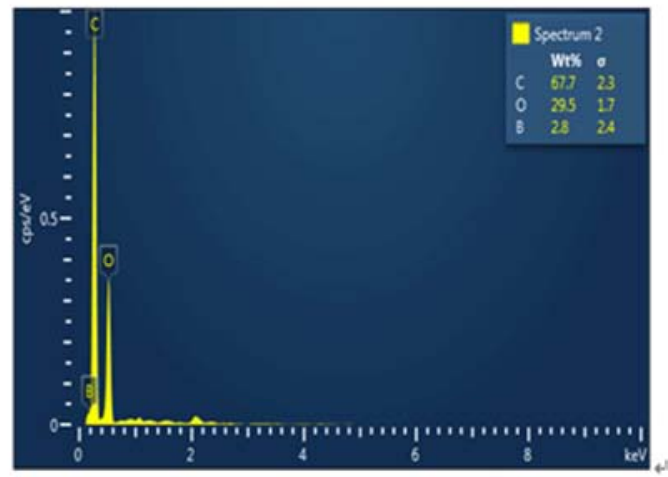

d)

Figure 3. SEM images (left) and corresponding spectrum (right) of tangential section of unleached wood blocks treated with boric acid alone (a, b) and boron-rosin solution (c, d). 
Fig. 4 shows SEM images corresponding spectrum of tangential sections of treated wood blocks after leaching. For wood blocks treated with boric acid alone, after leaching no crystal particles was detected by SEM observation (Fig. 4a). This revealed that after leaching, boric acid seemed to be completely leached out from treated wood. However, when the leached wood blocks treated with boron-rosin were

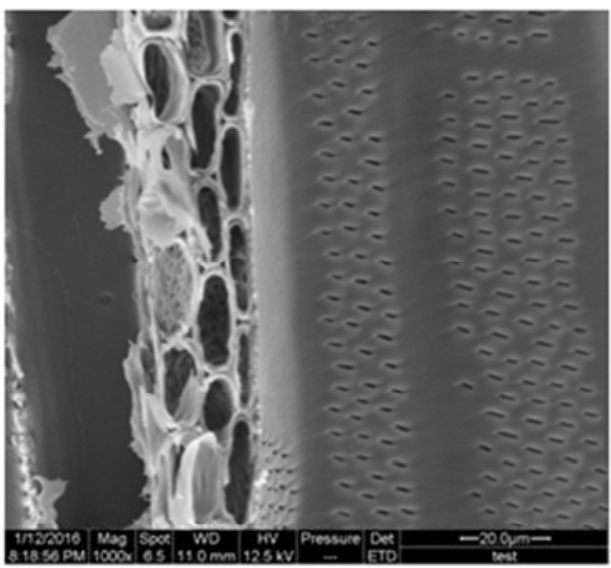

a)

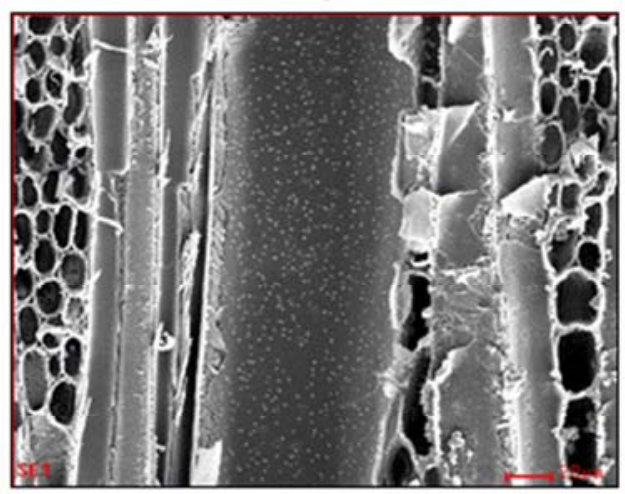

c) observed, the spherical agglomerates were still detected in the cell lumens (Fig. 4b). In addition, the spot analysis using SEMEDX proved that these agglomerates contained the element B (Fig. 4cd). This signifies that the rosin formed an adhesive film to cover the boron crystals, and the resulting boron was fixed into the wood blocks.

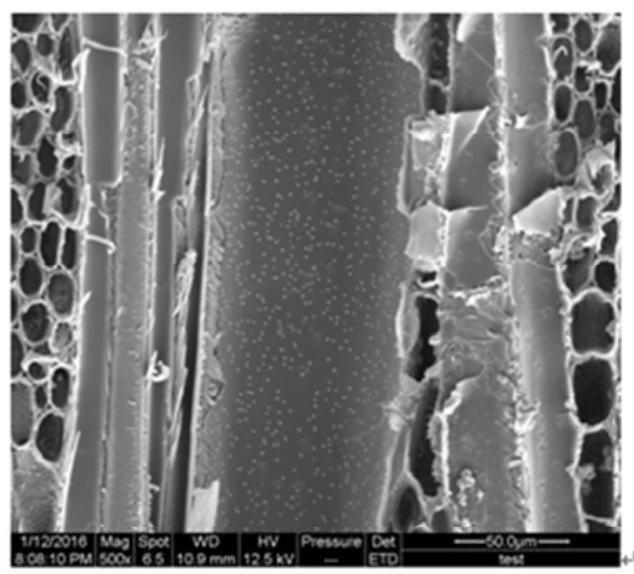

b)

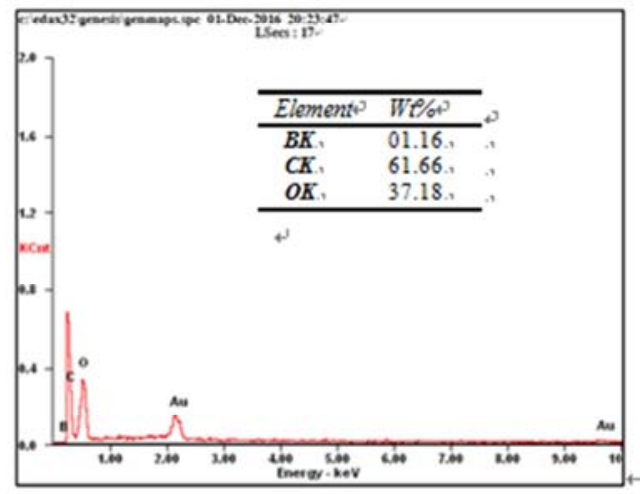

d)

Figure 4. SEM images and corresponding spectrum of tangential section of leached wood blocks treated with boron alone (a) and boron-rosin solution (b, c, d).

\section{Conclusions}

This study evaluated the effect of rosin sizing agent on the fixation of boron in Styrax tonkinensis wood. The results showed that using rosin alone or in combination with boric acid solution to impregnated Styrax tonkinensis wood by the impregnation method described did not influence the penetration of the preservative complexes into the wood blocks. The rosin sizing agent had have a certain effect on the fixation of boron in wood. The amount of boron ions released from the samples treated with the boron-rosin solution reduced by $16 \%$ compared with those from the samples treated with boric acid alone. The SEM-EDX analysis of the wood blocks treated with boron-rosin formulation confirmed that the preservative complexes containing B still existed in the cell lumens of wood, even after leaching. The use of rosin as fixing agents may contribute to lead to wood treated with boron based preservatives being more widely used.

\section{References}

[1] John MK, Chua HH, and Neufeld JH (1975). Application of improved azomethine- $\mathrm{H}$ method to the determination of boron in soils and plants. Analytical letters. 8 (8): 559-568.

[2] Köse Ck, Terzi E, Kartal SN, Erilkun B, Imamura Y (2011). Preliminary evaluation of boron release and biological resistance of wood treated with disodium octoborate tetrahydrate (DOT) and a water-repellent compound. African Journal of Biotechnology. 10 (10): 1833-1839.

[3] Li S, Thanh-Hien N. T, Han S, and Li J (2011). Application of rosin in wood preservation Chemistry and Industry of Forest Products. 31 (5), 117-121.

[4] Li S, Wang X, and Li J (2009). Effect of two water borne rosin on wood protection. Transactions of China Pulp and Paper 24 (supplement), 200-203. 
[5] Lesar B, Kralj P, Humar M (2009). Montan wax improves performance of boron-based wood preservatives. Int Biodeterior Biodegrad. 63(3): 306-310.

[6] Lesar B, Budija F, Kralj P, Petrǐc M, Humar M (2012). Leaching of boron from wood impregnated with preservative solutions based on boric acid and liquefied wood. Eur. J. Wood Prod. 70: 365-367.

[7] Nguyen TTH, Li J, Li S (2012). Effects of water-borne rosin on the fixation and decay resistance of copper-based preservative treated wood. Bioresour. 7(3): 3573-84.

[8] Nguyen TTH, Li S, Li J, and Liang T (2013). Microdistribution and fixation of a rosin-based micronized-copper preservative in poplar wood. International Biodeterioration \& Biodegradation. 83: 63-70.

[9] Obanda DN, Shupe TF, Barnes HM (2008). Reducing leaching of boron-based wood preservatives - a review of research. Bioresour Technol. 99(15): 7312-7322.

[10] Sen S, Tascioglu C, Trak K (2009). Fixation, leachability, and decay resistance of wood treated with some commercial extracts and wood preservative salts. International Biodeterioration \& Biodegradation. 63: 135-41.

[11] Song ZQ (2002). Fine Chemical Applications of Rosin (I)Composition and properties of rosin. Journal of Chemical Industry of Forest Products. 36(4): 29-33

[12] Temiz A, Alfredsen G, Eikenes M, Terziev N (2008). Decay resistance of wood treated with boric acid and tall oil derivates. Bioresource Technology. 99: 2102-2106.

[13] Tomak ED, Hughes M, Yildiz UC, Viitanen H (2011). The combined effects of boron and oil heat treatment on beech and Scots pine wood properties. Part 1: Boron leaching, thermogravimetric analysis, and chemical composition. J Mater Sci. 46: 598-607.

[14] Yalinkilic MK (2000). PhD Thesis, Kyoto University.

[15] Zhang G (2005). Progress of the studies on the cationic rosin size. China Pulp and Paper. 24: 57-61. 